\title{
К проблеме генезиса металлообработки синташтинской и петровской культур Южного Зауралья
}

\begin{abstract}
Аннотачия. В настоящее время назрела необходимость в сопоставлении инвентарного комплекса иветного металла культур по морфологии, химическому составу, технологии изготовления в связи с доминированием точки зрения о преемственном развитии между племенами синташтинской и петровской культур. Полученные аналитические данные по металлопроизводству культур вступают в противоречие с утверждением о синташтинских истоках петровского металлопроизводства. Собранные данные опровергают это предположение и дают возможность связать развитие металлопроизводства на рубеже средней-поздней бронзы с несколькими линиями развития обработки иветного металла в ямно-полтавкинской и катакомбной общностлх. Выводы статьи основаны на массовых результатах атомно-эмиссионного спектрометрического, ренгенофлюоресиентного (405 изделий; ИНХ СО РАН, ИА РАН), металлографического (320 изделий; ИПОС СО РАН) анализов. Морфологический обзор металлических коллекиий начала позднего бронзового века на территории от Дона до Ииима показывает использование идентичных орудий труда не только у синташтинских и петровских племен, а в гораздо более широком ареале степной и лесостепной зон Восточной Европы, Урала, Казахстана, что объяснимо с точки зрения появления эпохальных стандартных стереотипов металлопроизводства Западноазиатской провиниии, уходящих своими истоками в предшествующие ямно-полтавкинский и катакомбнъй периоды эпохи ранней и средней бронзы. Особенности технологических традииий синтаитинского и петровского производства вполне оббяснимы предшествуюшими трендами развития металлопроизводства в эпоху ранней и средней бронзы. В синташтинской культуре наблюдалась ориентаиия на производственные традииии степных ямных и катакомбных племен Северного Причерноморья и Предкавказъя в использовании преимущественно низколегированных мышыяковых бронз при господстве кузнечных технологий с низкотемпературными режимами обработки металла. Петровские металлурги, как и доно-волжские абашевские мастера, следовали традиииям приуральских ямно-полтавкинских металлургов с обработкой чистой меди, в том числе и окисленной с использованием литейных и кузнечных технологий.
\end{abstract}

Ключевые слова: Южное Зауралье, эпоха бронзы, петровская культура, синташтинскал культура, иветное металлопроизводство, металлография, древние технологии, типология иветного металла, морфология, технологические традииии.

Abstract. Now need for comparison of materials on morphology, the chemical composition, manufacturing techniques of an inventory complex of non-ferrous metal of cultures in connection with domination of the point of view about successive development between tribes of Sintashta and Petrovka Cultures has ripened. The obtained analytical data on metalproduction of cultures conflict to the statement about the Sintashta sources of Petrovka metalproduction. Collected data disprove this assumption and give the chance to connect development of metalproduction at a boundary of averagelate bronze with several lines of development of processing of non-ferrous metal in a Yamna-poltavka and catacomb communities. The article's conclusions are based on the mass results derived from the atomic emission spectroscopy (at the Institute of Inorganic Chemistry at the Siberian Branch of the Russian Academy of Sciences), X-ray fluorescence (at the Institute of Archaeology at the Russian Academy of Sciences) (405 products) and metallographic (at the Institute for the Study of the Northern Expansion at the Siberian Branch of the Russian Academy of Sciences, 320 products) analyses. The morphological review of metal collections of the beginning of a late bronze age in the territory from Don to Ishim shows use of identical instruments of labor not only at the Sintashta and Petrovka tribes, and in much wider area of a steppe and forest-steppe strip of Eastern Europe, the Urals, Kazakhstan that is explainable from the point of view of emergence of epoch-making standard stereotypes of metalproduction of the West Asian province going the sources to the previous Yamnapoltavk a and catacomb periods of early and average bronze. Features of technological traditions of Sintashta and Petrovka 


\section{Исторический журнал: научные исследования № 6 (36) • 2016}

DOI: $10.7256 / 2222-1972.2016 .6 .20791$

production are quite explainable the previous trends of development of metalproduction during of early and average bronze. In Sintashta Culture orientation to production traditions of steppe Yamna-poltavka and catacomb tribes of Northern Black Sea and Ciscaucasia in the use of predominantly low-alloy arsenic bronzes under the domination of the forging technique that uses low-temperature metal working. Petrovka blacksmiths, similar to Don-Volga Abashevo masters, continued the stable tradition of the Ural Yamna-Poltavka blacksmiths of handling pure copper, including oxidised copper with the use of casting and forging techniques.

Key words: South Ural, Bronze Age, Petrovka culture, Sintashta culture, nonferrous metal production, metallography, Ancient technologies, nonferrous metal typology, morphology, technological traditions.

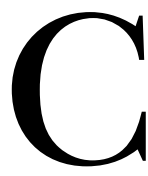

инташтинский и петровский очаги Южного Зауралья наряду с сейминскотурбинскими центрами металлопроизводства являлись наиболее крупными в системе Евразийской (Западноазиатской) металлургической провинции на первом этапе ее существования на рубеже III-II тыс. до н. э. XVII в. до н. э. Территориально синташтинские и петровские памятники расположены в Челябинской, Курганской, Оренбургской областях, северо-западном Казахстане. Ареал петровских комплексов простирается и далее на восток в Приишимье и Центральный Казахстан. Калиброванные радиоуглеродные датировки памятников синташтинской культуры соответствуют 2200-1650 гг. до н. э. Примерно в таком же диапазоне датированы абашевские материалы 2200-1650 гг. до н. э., позже - петровские (1880-1750 гг. до н. э.) [1, 85; 2, 142]. По данным Е.Н. Черных петровские комплексы датированы несколько ранее - 2100-1650 гг. до н.э. [3, 15].

Большинство исследователей - Н.Б. Виноградов, В. В. Ткачев, А. В. Епимахов связывают генезис синташтинской культуры с культурами катакомбной общности, оказавшими влияние на формирование синташтинского населения совместно с аборигенными энеолитическими культурами Южного Урала [4, 78-83; 5, 76-80] или же с преобладающим катакомбно-абашевским воздействием [6, 275-279]. При этом Н. Б. Виноградов предположил возможность опосредованного участия и ямно-полтавкинского населения Южного Приуралья в генезисе памятников синташтинского типа в результате миграций из степной зоны Волго-Уралья. Происхождение памятников петровского типа по мнению Н. Б. Виноградова связано с наследием и распространением уже синташтинских культурных стереотипов в среде местного энеолитического населения одновременно как в Южном Зауралье, так и в Северном и Центральном Казахстане [4, 141]. В. В. Ткачев, придерживаясь сходной точкизрения, понимаетсинташтинскую культуру как генератор раннеалакульского (петровского) культурогенеза на Южном Урале и Западном Казахстане [6, 324-325]. Основанием для этих заключений послужили стратиграфические наблюдения, данные радиоуглеродного датирования, анализ керамических материалов. Обнаружение идентичных форм металлических изделий в материалах культур также трактуется как наследие синташтинского металлопроизводства, в том числе и технологических традиций. Накопленная значительная источниковая база по металлопроизводству культур начала позднего бронзового века в виде готовых изделий, слитков, шлаков, литейных форм, кусков руды, остатков плавильных печей, обобщение аналитических исследований позволили внести ясность в решение проблем, связанных с процессами формирования металлургических традиций, определением уровня развития и организации производственной деятельности древнего населения [7-14]. Собранные данные (морфологотипологическая характеристика, исследование рецептуры сплавов, технологических приемов изготовления инвентаря) вступают в противоречие с изложенной выше точкой зрения о синташтинских истоках петровского металлопроизводства, поэтому возникла необходимость в сопоставлении специфических черт металлообработки этих культур или культурных типов по Н. Б. Виноградову.

Основные результаты и выводы основаны на данных морфолого-типологической характеристики цветного инвентаря культур, результатах атомно-эмиссионного спектрометрического и ренгенофлюоресцентного (405 изделий; Институт неорганической химии СО РАН, Института археологии РАН), а также металлографического анализов (320 изделий; Институт проблем освоения Севера СО РАН). Результаты исследования синташтинского металлопроизводства достаточно подробно были изложены ранее [15], в данной статье приводятся в тезисном виде. Подавляющее большинство бронзовых орудий и украшений (96\% от общего количества учтенных 599 изделий) происходит из погребальных 
комплексов, тогда как доля поселенческого металла составляет всего 4\%. Для синташтинской культуры характерно широкое использование металла, прежде всего в ритуальных погребальных целях. Орудия представлены плотницким инструментарием (топоры, тесла, долота, ножи, шилья), однако чаще всего находили ножи и шилья, доля которых доходила до половины найденных орудий труда. Выделены ведущие типы изделий синташтинского центра производства, к которым относятся вислообушные топоры с бойками, тесла с параллельными и трапециевидными гранями, долота стержневидные, ножи с удлиненным узким насадом, ножи с едва выделенным черешком подтреугольной формы, ножи с перекрестием и перехватом, гарпуны, черешковые наконечники стрел, кованые втульчатые наконечники копий. Численность предметов вооружения (наконечники стрел, копий) и украшений (накосники, очковидные подвески, кольца со щитками, браслеты, подвески в полтора оборота) незначительна и сосредоточена всего лишь в нескольких погребениях, учитывая к тому же низкую металлоемкость бусин из браслетов и подвесок из накосников (рис. 1).

Цветной металл петровской культуры Южного Зауралья (Среднего Притоболья) насчитывает 391 экз., из которых около 60\% изделий обнаружены на поселениях, $40 \%$ - в составе погребальных комплексов. В поселенческих комплексах преобладают орудия труда, слитки, заготовки. В погребальном инвентаре петровской культуры, в отличие от синташтинской, обнаружены большей частью украшения $(78,7 \%)$ и орудия труда $(19,8 \%)$. Эти различия в видовом составе инвентаря сказались на особенностях распределения металлургических групп поселенческого и погребального инвентаря. Из специфических петровских типов следует упомянуть вислообушные топоры с Г-образным абрисом, однолезвийные и двулезвийные ножи с длинной выделенной рукоятью, серпы бесчеренковые с малой степенью изогнутости и сильноизогнутые, кованые втульчатые стрелы, копья, литые крестовидные подвески, накосники, прутковые браслеты и кольца со спиралевидными щитками, круглые бляшки с разнообразным пуансонным орнаментом (рис. 2).

В морфологическом облике как синташтинских, так и петровских орудий, безусловно, отчетливо видны реминисценции Циркумпонтийской провинции, прежде всего ямно-полтавкинских и катакомбных очагов, в частности в форме тесел, втульчатых копий, крюков, долот, ножей с удлиненным узким насадом, черенковых долот, шильев с упором-утолщением, хотя все эти предметы утратили былую массивность. Ближайшие аналоги орудийного комплекса синташтинской и петровской культур сосредоточены среди инвентаря культур ранней фазы Евразийской (Западноазиатской) металлургической провинции лесостепной и степной зон Восточной Европы абашевского, потаповского, покровского и раннесрубного металлокомплексов. Большинство типов орудий и украшений представлены общеевразийскими формами, присущими упомянутым культурам начальной фазы ЕАМП (ЗАМП), в значительно меньшей степени - металлопроизводству сейминско-турбинских племен, которые имели более продвинутые и развитые литейные технологии. К числу общеевразийских типов относятся тесла с параллельными и трапециевидными гранями, втульчатые кованые долота, стержневидные долота, чеканы, узколезвийные серпы с малой степенью изогнутости, несколько типов черенковых ножей: с удлиненным узким насадом; со слабо выделенным черенком без перехвата; с боковыми выемками, отделяющими черенок от лезвия; с подромбическим черенком, перехватом, без перекрестия; с черенком, перехватом, перекрестием. Наиболее массовой категорией орудий в указанных культурах являются ножи с ромбическим черенком, перекрестьем и перехватом (134 экз., перечень дополнен 6 әкз. из петровских погребений мог. Бестамак, Степное 7) [16, табл. 1]. Чаще всего подобные ножи находятся в синташтинских погребальных комплексах (46 экз.). Они характерны для донских и уральских абашевских памятников (31 экз.). В меньшем количестве (примерно по 4-25 экз.) они обнаружены в покровских и раннесрубных (25 экз.), потаповских (4 экз.), петровских (18 экз.), сейминско-турбинских (8 экз.) памятниках. В процессе картографирования выявлено распределение ножей в широтном направлении с ареалом, приуроченным к лесостепной и степной евразийским зонам от Среднего Подонья до Притоболья. В нуртайских памятниках Центрального Казахстана они неизвестны, вместе с тем в Сары-Арке более отчетливо проявляются в морфологии цветного металла реминисценции катакомбного металлопроизводства.

Появление общих типов металлических изделий в абашевских, синташтинских, покровских, потаповских, сейминско-турбинских, петровских популяциях следует рассматривать не 


\section{Исторический журнал: научные исследования № 6 (36) • 2016}

DOI: $10.7256 / 2222-1972.2016 .6 .20791$
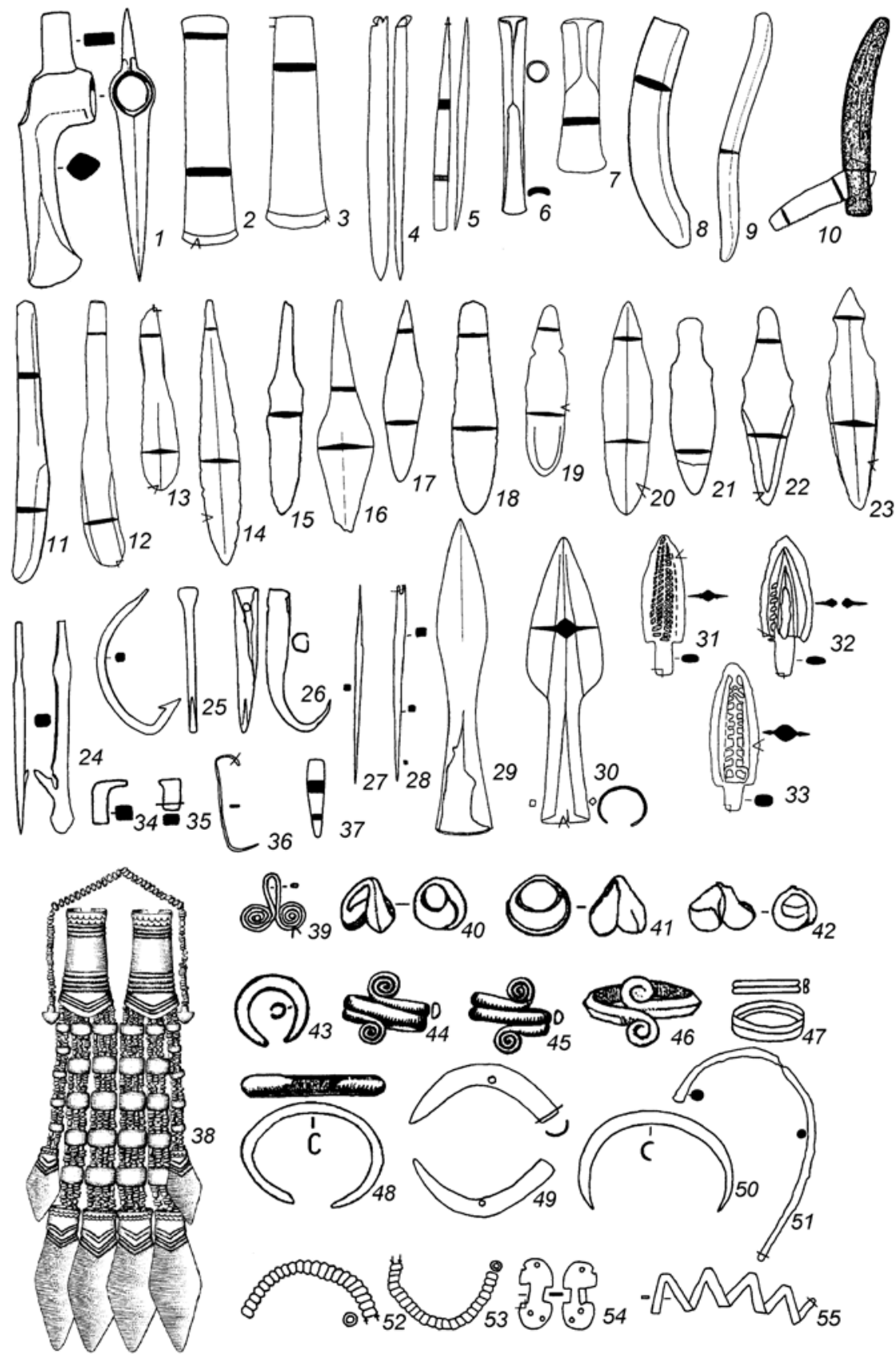

Рис. 1. Основные типы орудий труда, вооружения, украшений синташтинской культуры (секущими линиями показаны срезы на шлифы).

1, 9, 16, 17, 21, 24, 38, 44, 45 - мог. Синташтинский большой; 2, 3, 14, 28, 29, 31-33, 41, 46- мог.

Синташтинский 2; 4, 5, 12, 20, 30, 37, 47, 51, 54, 55 - Каменный Амбар 5; 6, 26, 27 - Большекараганский мог.;

7 - мог. Танаберген 2; 8, 25, 48 - пос. Синташта; 10, 18 - мог. у горы Березовой; 11, 15, 40- мог.

Синташтинский $1 ; 13,19,22,23,34-36,39,42,49,50,52,53$ - мог. Кривое Озеро; 43- мог. Обилькин Луг 3.

только как следствие интенсивных металлургических контактов в ходе мощных миграционных движений племенных групп с запада и юго-запада на восток и северо-восток, в т.ч. и кланов металлургов с целью поиска новых сырьевых ис- точников металла $[17,24-25]$. По всей видимости, это также должно объясняться существованием общей подосновы в генезисе металлопроизводства культур ранней фазы ЕАМП - в виде ямно-полтавкинского и катакомбного субстрата. 

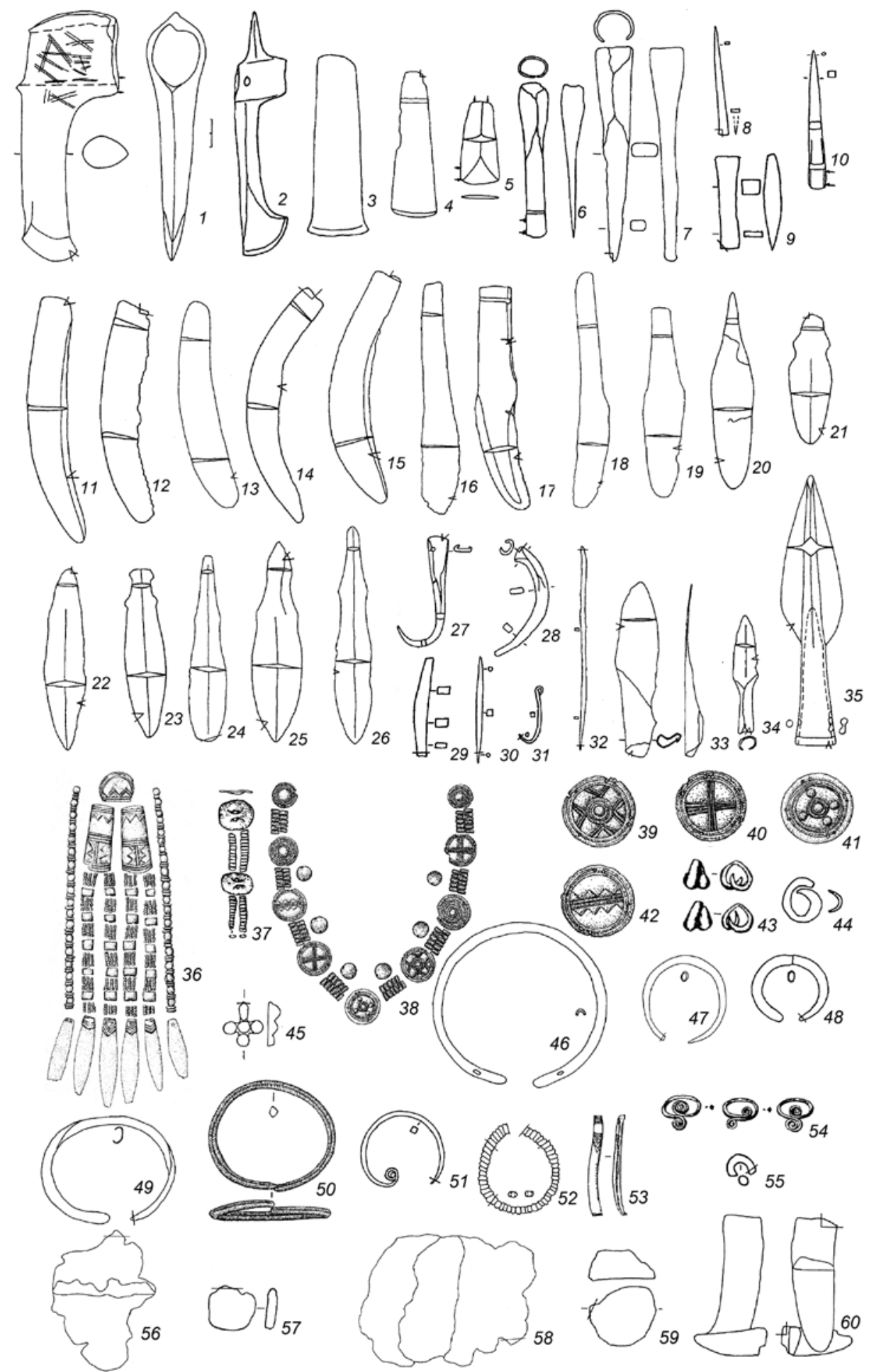

คि 55

Рис. 2. Основные типы орудий труда, вооружения, украшений петровской культуры (секущими линиями показаны срезы на шлифы).

$1,5,6,10,11,17,21,22,28,45,53$ - пос. Кулевчи $3 ; 2,36,38-42,46,50$ - мог.

Степное 7; 3, 26, 37, 44, 48, 49, 51, 54 - мог. Верхняя Алабуга; 4, 25, 35 - мог.

Кривое Озеро; 7, 8, 12, 14, 15, 23, 27, 32, 52, 56, 58, 60-пос. Устье; 9, 19, 31, 47, 57 - пос.

Убаган 2; 13, 33 - пос. Нижнеингальское; 16- пос. Камышное 2; 18, 24 - Курганская обл. (сл. нах.);

20, 30 - мог. Озерное 1; 29, 34 - пос. Убаган 1; 43, 46-мог. Кулевчи 6; 55, 59 - пос. Убаган 3. 


\section{Исторический журнал: научные исследования № 6 (36) • 2016}

DOI: $10.7256 / 2222-1972.2016 .6 .20791$

Е. Н. Черных писал, что основную роль в передаче традиций наследия ЦМП сыграли центры северо-восточной зоны провинции и прежде всего комплексы ямно-полтавкинской общности. Достаточно большая степень типологического сходства металла синташтинской культуры с металлопроизводством синхронной абашевской, а в ряде случаев идентичность форм керамики и металлических изделий привела исследователя к мысли о существовании обширной абашевосинташтинской археологической общности в рамках «синдрома степной культурной непрерывности» $[1,75-79]$.

В результате влияния абашевских традиций производства в синхронных культурах Евразии появились серпы, струги-скобели, двулезвийные ножи с прямой рукоятью, черенковые ножи с перехватом, без перекрестья. Хотя надо отметить, что в инвентаре сопредельных культур отсутствуют такие традиционные формы абашевского металла, как грацильные узковислообушные топорики с дуговидным абрисом, массивные прутковые браслеты и бляшки-розетки. Исходный центр ножей с удлиненным, сужающимся к окончанию черенком и перекрестьем находился в Поволжье в среде вольско-лбищенских, покровских, потаповских и раннесрубных племен. В синташтинских и петровских погребениях обнаружены изделия, которые являются явно импортными из сейминско-турбинских очагов, - литые наконечники копий, бесчеренковые ножи, ножи с широким прямым черенком, пилки (мог. Кривое Озеро, Степное 7, гора Березовая) [7; 12; 18, 75-79].

Украшения, выполняя функции этнических маркеров племен, в меньшей степени имеют выраженную универсальность. Лишь подвески в полтора оборота, очковидные украшения, многовитковые кольца, круглые трубчатые подвески характерны для абашевских, петровских, синташтинских племен. Анализ морфологии синташтинских украшений указывает на наличие типов, маркирующих достаточно тесные связи с населением петровской культуры. В числе последних накосники, их детали, кольца со спиралевидными щитками, браслеты из бусин, сконцентрированные в подавляющем большинстве в погребальных комплексах петровской, нуртайской, алакульской, атасуской культур. Выпукло-вогнутые в сечении браслеты изготовлены с добавлением оловянно-свинцовой лигатуры, традиционной также для петровских популяций. Факт нахождения этих предметов в женских погребениях вполне может комментироваться как свидетельство межэтнических браков, хотя часть исследователей видят в этом свидетельство наследования синташтинских традиций петровскими племенами [4]. Реминисценции катакомбных воздействий просматриваются в наличии посоховидной булавки, подвесок в полтора оборота, в присутствии украшений, изготовленных из бронзы с добавкой цинка [15].

O степени интенсивности связей между турбинскими, абашевскими, петровскими популяциями свидетельствуют находки синташтинских копий, ножей, тесел в Ростовке, Кондрашкинском кургане, Верхней Алабуге, турбинских литых копий в петровском и позднеабашевских погребениях могильников Кривое Озеро, Селезни 2, петровского ножа в Сатыге 6. В этом ряду фактов, свидетельствующих о прямых контактах синташтинского, петровского, абашевского населения, весьма примечательны погребения могильников Степное 7, Озерное, Токанай 1, Бестамак в Притоболье, Восточно-Курайлинский I, Малоюлдашево в Оренбуржье, Халвай в Казахстане, содержавшие металлические изделия и керамику синташтинского, абашевского и петровского типов [19-22; 6]. Наряду с обменом готовыми изделиями происходила и поставка полосовых и тигельных слитков с легирующими компонентами Sn и As до 14-15\%, бинарных сплавов олово-свинец в виде колечек от металлургов синташтинской культуры и из алтайских рудных источников [16].

Статистическая обработка данных аналитического исследования показала, что при совпадении морфолого-типологических стандартов орудийных комплексов отсутствует единообразие как в рецептуре сплавов, так и в технологии изготовления цветного металла мастерами этих племенных групп (рис. 3).

Данные о химическом составе металла синташтинской культуры были получены по 113 изделиям [15]. Металлические предметы распределены на группы следующим образом: медь и сплавы на ее основе $(88,1 \%)$, биллоны и серебро $(7,8 \%)$, золото $(4,1 \%)$. Медь и сплавы на ее основе подразделяются на девять металлургических групп: чистой меди, двойных сплавов (мышьяковой бронзы), латуни (сплава меди с цинком), а также сложных трех-, четырех-, пятикомпонентных сплавов с лигатурой As, $\mathrm{Sn}, \mathrm{Pb}, \mathrm{Zn}$. Ведущей металлургической группой, безусловно, являются бинарные сплавы медь-мышьяк, их доля составляет 79,9\% от общего количества проанали- 


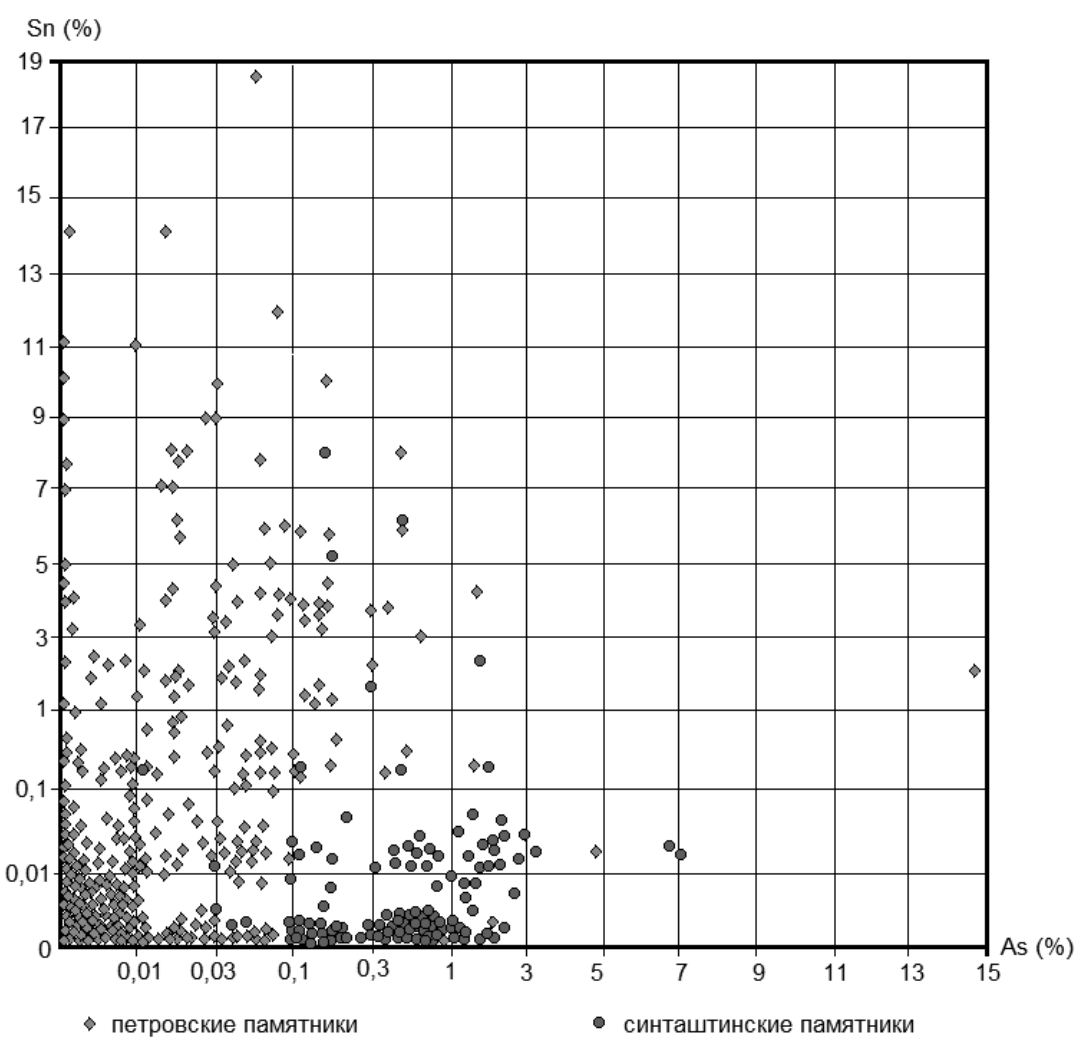

Рис. 3. Корреляция концентраций примесей Sn-As к меди металла петровской и синташтинской культур.

зированных изделий (концентрация мышьяка 0,1-7 \%). На графике корреляции концентраций примесей $\mathrm{Sn}-\mathrm{As}$ к меди металла петровской и синташтинской культур четко видно вычленение синташтинского металла с концентрациями As от 0,1 до $7 \%$, с микропримесями олова до 0,1 \% (рис. 3). Сучетом количества предметов, изготовленных из многокомпонентных сплавов, реальная доля сплавов, в которых присутствует мышьяк, доходит до 92,6\%. Мышьяковые бронзы синташтинской культуры относятся к категории низколегированных - 88,1\% изделий имеют в своем составе примесь мышьяка до $3 \%$. Группа чистой меди небольшая, она насчитывает всего шесть предметов. Численность остальных металлургических групп незначительна - от 4 до 1 предмета. Оловянная бронза, в целом не характерная для синташтинского производства, использовалась в основном на изготовление украшений - браслетов, подвесок, а также иглы, ножа. Наличие небольшой серии оловянных бронз объясняется контактами с турбинскими и петровскими племенами, которые являлись основными посредниками в распространении оловянной лигатуры. Группа мышьяковых бронз представлена почти исключительно орудиями труда и бусинами браслетов.

В процессе проведенного металлографического исследования срезов изделий из цветного металла (104 экз.) установлено, что ведущими в синташтинском металлопроизводстве были кузнечные технологии: получение орудий и украшений ковкой с нагревами при температурах 400$500{ }^{\circ} \mathrm{C}, 600-700{ }^{\circ} \mathrm{C}$ либо только холодной ковкой и холодной в сочетании с отжигами. Получение полностью готовых изделий в формах и литье с косметической проковкой лезвий фиксировалось крайне редко. Синташтинские литейщики следовали своим традиционным технологическим принципам с преобладанием кузнечных схем, ими так и не было освоено сложное литье с тонким фасонным профилем. При изготовлении только трети орудий труда использовалась схема предварительного литья предметов, которые затем проковывали с использованием средних степеней обжатия до 60-70\% (тесла, ножи).

Показательно появление большого числа высококачественных изделий с явными чертами применения профессиональной технологии, выполненных практически по единым стан- 


\section{Исторический журнал: научные исследования № 6 (36) • 2016}

DOI: $10.7256 / 2222-1972.2016 .6 .20791$

дартизированным технологическим канонам. Сохраняется основная рецептура сплавов, присущая причерноморским и предкавказским очагам ЦМП с использованием мышьяковых бронз, зафиксировано и присутствие многокомпонентных латуней. В отличие от очагов ЦМП сплавы подбирались низколегированные, содержащие до $2 \%$ мышьяка.

Металлические изделия петровской культуры представлены медью и сплавами на ее основе (292 экз.). Помимо меди и сплавов на ее основе в единичных экземплярах обнаружены украшения из биллона, золота, сплава олово-свинец. Цветной металл петровской культуры зауральского очага распределяется на шесть металлургических групп - чистой меди $(60,9 \%)$, оловянной (30,6\%; содержание олова $0,4-18 \%)$, комплексной оловянно-мышьяковой $(6,4 \%$; содержание Sn 0,4-10\%, As - 0,4-15\%) (рис. 3). Оставшиеся три группы представлены единичными изделиями. В петровский период выстраивается рецептура сплавов, употребляемых впоследствии в алакульской, алексеевско-саргаринской культурах с возрастанием все большего удельного веса оловянных бронз и уменьшением числа изделий из чистой меди.

Сырьем для изготовления орудийного комплекса служили чистая медь, низколегированные оловянная, в меньшей степени комплексные оловянно-мышьяковые, мышьяковые бронзы. Группа чистой меди содержала так называемую окисленную медь численностью примерно до 25\%, которая маркируется в процессе металлографического анализа наличием участков эвтектики $\mathrm{Cu}-\mathrm{Cu}_{2} \mathrm{O}$. Из окисленной меди изготовлены орудия, полуфабрикаты, слитки, несколько украшений. Плавка и переработка окисленной меди достаточно сложна, поскольку предполагает достижение более высоких температур плавления металла, нежели при плавке легированных бронз, наличие навыков умелого предохранения жидкого расплава от избыточного окисления, навыков манипулирования металлом при горячей обработке при температуре 900-1000 ${ }^{\circ} \mathrm{C}$. В современных условиях медь подобного класса изготавливается лишь в условиях вакуумной плавки. Экспериментальные работы археологов, связанные с получением этой меди, в том числе на Каргалах, также были неудачными [23, 79-80]. Методами обработки окисленной меди в совершенстве владели металлурги ямной и вольско-лбищенской культур Приуралья, только этот вид сырья был основным в очагах Бал-
кано-Карпатской металлургической провинции [24]. Изделия из окисленной меди отсутствуют в инвентаре синташтинской культуры. В то же время коллекция абашевской культуры представлена наряду с мышьяковой медью группой МП (медистых песчаников), численность которой является, по данным Е. Н. Черных, преобладающей по мере продвижения от Урала на запад - в Среднее Поволжье и Подонье [18, 80-83]. Использование окисленной руды типа малахита, азурита, куприта зафиксировано, в том числе и с помощью металлографических методов, в донском абашевском, центральноказахстанском нуртайском, алтайском елунинском, западносибирском сейминско-турбинском металлопроизводстве [15; 25; 26].

Основным сырьем для изготовления украшений - прежде всего браслетов, крестовидной подвески - выступала высоколегированная оловянная бронза с концентрациями олова до $18 \%$, в меньшей степени - чистая медь.

Рассматривая особенности изготовления цветного инвентаря - орудий труда, украшений, полуфабрикатов (исследовано методами металлографического анализа 216 предметов), в первую очередь следует отметить многообразие используемых технологических схем с различными режимами термообработки. Преобладали кузнечные схемы получения изделий $(62,4 \%$ от выборки). Литых предметов, доработанных далее ковкой, в коллекции выявлено только около трети $(35,7 \%)$, все они входят в группу орудий труда - серпы, ножи, тесла, топоры. Орудия труда изготавливали в основном в процессе литья в разъемные формы, после чего следовала доработка ковкой рабочих поверхностей изделий. Способ кузнечной формообразующей ковки использовался только при получении мелких орудий.

В процессе кузнечной формовки использовались режимы горячей ковки 600-800 ${ }^{\circ} \mathrm{C}$ $(35,4 \%)$ либо низкие температуры начальной стадии рекристаллизации металла 250-400 ${ }^{\circ} \mathrm{C}$ $(31 \%)$. Популярной была также ковка по холодному металлу или вхолодную с промежуточными отжигами $(21,5 \%)$. Примерно десятая часть орудий обработана с помощью достаточно сложной технологии ковки в режиме предплавильных температур - 900-1000 ${ }^{\circ} \mathrm{C}(10,2 \%)$. Этот режим термообработки был широко распространен у ямников Приуралья [15].

Часто получали орудия и заготовки способом пакетной сварки - как при низких, так и при предплавильных температурах $(8,8 \%)$. 
Особые варианты технологии выявлены на примере этнических маркеров носителей петровских традиций - крестообразных подвесок и браслетов со спиралевидными завитками: использование литых технологий в разъемных формах из высоколегированной оловянной бронзы (до 18\%), предварительных отжигов гомогенизации для повышения пластичности металла, горячей ковки.

Морфологический обзор металлических коллекций начала позднего бронзового века на территории от Дона до Ишима показывает использование идентичных орудий труда не только у синташтинских и петровских племен, а в гораздо более широком ареале степной и лесостепной полосы Восточной Европы, Урала, Казахстана. Это объяснимо с точки зрения появления эпохальных стандартных стереотипов металлопроизводства Западноазиатской провинции, уходящей своими истоками в предшествующий ямно-полтавкинский и катакомбный пласт эпохи ранней и средней бронзы. Однако при наличии сходных типов орудий труда рецептура сплавов и технологические схемы изготовления, используемые в разных центрах металлопроизводства подобного единообразия не демонстрируют. Этот феномен объясним технологическими традициями, существовавшими в раннем и среднем бронзовом веке. По данным Е. Н. Черных, в Волго-Уралье в ямно-полтавкинское время преобладала группа чистой меди $(78,3 \%)$, а также использовались мышьяковые бронзы $(21,7 \%)[1,67]$. В низовьях Дона, Донца, Калмыкии в ямный и катакомбный периоды As-бронзы являлись основной металлургической группой $(64,7 \%)$ [1, 67-69; 27]. Таким образом, предшествующие тренды развития металлопроизводства в эпоху ранней и средней бронзы объясняют различие в технологических традициях синташтинского и петровского про- изводства при отсутствии преемственности между ними. У первых наблюдалась ориентация на производственные традиции степных ямных и катакомбных Северного Причерноморья и Предкавказья в использовании преимущественно низколегированных мышьяковых бронз при господстве кузнечных технологий с низкотемпературными режимами обработки металла для предотвращения возгонки ядовитых летучих паров мышьяка при повышении температуры. Петровские металлурги, как возможно и доноволжские абашевские мастера, спустя несколько веков начали использовать архаичные традиции приуральских ямно-полтавкинских металлургов с обработкой чистой меди, в том числе и окисленной с использованием кузнечных и литейных технологий в режимах температур красного каления металла, а также используя термообработку предплавильных температур 900-1000 ${ }^{\circ} \mathrm{C}$. Кстати, Т. М. Потемкина выделила в 1 группе погребений могильника Верхняя Алабуга сосуды, сходные с позднеполтавкинской керамикой Поволжья и петровской Приишимья [13, 179-181]. Хотя, казалось бы, в случае преемственности традиций, петровские мастера вполне могли перенять опыт плавки и обработки мышьяковых бронз, к тому требовавших при переделке более низких температур. Результаты исследования антропологического материала из синташтинских, петровских, срубно-алакульских памятников показали гетерогенность, разнородность населения как на уровне отдельных могильников, так и на уровне культур. По мнению Е. П. Китова население культур находилось на стадии смешения, формирование общего морфологического типа еще не произошло [28, 18-23]. Эти важные наблюдения также не подтверждают наличие преемственности в развитии между синташтинской и петровской культурами (или культурными типами).

\section{Библиография:}

1. Черных Е. Н. Каргалы: феномен и парадоксы развития. Каргалы в системе металлургических провинций. Потаенная (сакральная) жизнь архаичных горняков и металлургов // Каргалы. М.: Языки славянской культуры, 2007. Т. 5. 200 с.

2. Молодин В. И., Епимахов А. В., Марченко Ж. В. Радиоуглеродная хронология культур эпохи бронзы Урала и юга Западной Сибири: принципы и подходы, достижения и проблемы // Вестник НГУ. Серия: История, филология. 2014. Т. 13. Вып. 3: Археология и этнография. С. 136-167.

3. Черных Е. Н., Орловская Л. Б. Радиоуглеродная хронология культур Западной Евразии в эпоху раннего металла // Естественнонаучные методы исследований и парадигма современной археологии: Материалы Всероссийской научной конференции, Москва, 8-11 декабря 2015. М.: Языки славянской культуры, 2015. С. 8-18.

4. Виноградов Н. Б. Степи Южного Урала и Казахстана в первые века II тыс. до н. э. (памятники синташтинского и петровского типа). Челябинск: Абрис, 2011. 175 с.

5. Епимахов А. В. Южное Зауралье в эпоху средней бронзы. Челябинск: Издательство ЮУрГУ, 2002. 170 с.

6. Ткачев В. В. Степи Южного Приуралья и Западного Казахстана на рубеже эпох средней и поздней бронзы. Актобе: Актюбинский областной центр истории, этнографии и археологии, 2007. 384 с. 


\section{Исторический журнал: научные исследования № 6 (36) • 2016}

DOI: $10.7256 / 2222-1972.2016 .6 .20791$

7. Виноградов Н. Б. Могильник бронзового века Кривое Озеро в Южном Зауралье. Челябинск: Южно-Уральское книжное издательство, 2003. 362 с.

8. Генинг В. Ф., Зданович Г. Б., Генинг В. В. Синташта: археологические памятники арийских племен урало-казахстанских степей. Челябинск: Южно-Уральское книжное издательство, 1992. 408 с.

9. Древнее Устье: укрепленное поселение бронзового века в Южном Зауралье / Отв. ред. Н. Б. Виноградов. Челябинск: Абрис, 2013. 482 c.

10. Епимахов А. В. Ранние комплексные общества севера Центральной Евразии. Челябинск: Челябинский дом печати, 2005. $192 \mathrm{c}$.

11. Зданович Г. Б. Бронзовый век Урало-Казахстанских степей. Свердловск: Уральский университет, 1988. $184 \mathrm{c.}$

12. Куприянова Е. В., Зданович Д. Г. Древности лесостепного Зауралья: могильник Степное VII. Челябинск: Энциклопедия, 2015. $196 \mathrm{c}$.

13. Потемкина Т. М. Бронзовый век лесостепного Притоболья. М.: Наука, 1985. 376 с.

14. Ткачев А. А. Центральный Казахстан в эпоху бронзы. Тюмень: Тюменский нефтегазовый университет, 2002. Ч. 1.289 с.

15. Дегтярева А.Д. Древнее металлопроизводство Южного Зауралья. Новосибирск: Наука, 2010. 162 с.

16. Виноградов Н. Б., Дегтярева А. Д., Кузьминых С. В. Металлургия и металлообработка в жизни обитателей укрепленного поселения Устье 1 // Вестник археологии, антропологии и этнографии. 2013. № 3 (22). С. 4-30.

17. Черных Е. Н. Металл и древние культуры: Узловые проблемы исследования // Естественнонаучные методы в археологии. М.: Наука, 1989. С. 14-30.

18. Черных Е. Н., Кузьминых С. В. Древняя металлургия Северной Евразии. М.: Наука, 1989. 320 с.

19. Калиева С. С., Логвин В. Н. Могильник у поселения Бестамак (предварительное сообщение) // Вестник археологии, антропологии и этнографии. 2008. № 9. С. 32-58.

20. Логвин В. Н. Могильник Токанай 1 и проблема соотношения «петровских» и «синташтинских» памятников // Западная и Южная Сибирь в древности. Барнаул: Издательство Алтайского университета, 2005. С. 190-194.

21. Логвин А. В., Шевнина И. В. Курган Халвай 3 (предварительное сообщение) // Маргулановские чтения 2011. Материалы международной археологической конференции. Астана: ЕНУ имени Л. Н. Гумилева, 2011. С. 291-296.

22. Моргунова Н. Л., Евгеньев А. А., Купцова Л. В. Погребальный комплекс синташтинского времени на поселении Малоюлдашево І в Западном Оренбуржье // Археология, этнография и антропология Евразии. 2015. № 2 (43). С. 64-71.

23. Ровира С. Технология выплавки меди в эпоху поздней бронзы на Каргалах // Российская археология. 2005 . № 4. C. 79-83.

24. Рындина Н. В. Древнейшее металлообрабатывающее производство Юго-Восточной Европы. М.: Эдиториал УРСС, 1998. $288 \mathrm{c}$.

25. Дегтярева А. Д., Грушин С. П., Шайхутдинов В. М. Металлообработка населения елунинской культуры Верхней Оби (предварительные результаты металлографического исследования) // Вестник археологии, антропологии и этнографии. 2010. № 2 (13). С. 27-35.

26. Дегтярева А. Д., Кузьминых С. В. Результаты аналитического исследования металлических изделий могильника Сатыга XVI // Сатыга XVI: сейминско-турбинский могильник в таежной зоне Западной Сибири. Екатеринбург: Уральский рабочий, 2011. С. 37-44.

27. Гак Е.И. Металлообрабатывающее производство катакомбных племен степного Предкавказья, Нижнего Дона и Северского Донца: Автореф. дис. ... канд. ист. наук. М.: МГУ им. М.В. Ломоносова, 2005. 27 с.

28. Китов Е. П. Палеоантропология населения Южного Урала эпохи бронзы: Автореф. дис. ... канд. ист. наук. М.: Институт этнологии и антропологии РАН, 2011. 26 с.

\section{References (transliterated):}

1. Chernykh E. N. Kargaly: fenomen i paradoksy razvitiya. Kargaly v sisteme metallurgicheskikh provintsii. Potaennaya (sakral'naya) zhizn' arkhaichnykh gornyakov i metallurgov // Kargaly. M.: Yazyki slavyanskoi kul'tury, 2007. T. 5. $200 \mathrm{~s}$.

2. Molodin V. I., Epimakhov A. V., Marchenko Zh. V. Radiouglerodnaya khronologiya kul'tur epokhi bronzy Urala i yuga Zapadnoi Sibiri: printsipy i podkhody, dostizheniya i problemy // Vestnik NGU. Seriya: Istoriya, filologiya. 2014. T. 13. Vyp. 3: Arkheologiya i etnografiya. S. 136-167.

3. Chernykh E. N., Orlovskaya L. B. Radiouglerodnaya khronologiya kul'tur Zapadnoi Evrazii v epokhu rannego metalla // Estestvennonauchnye metody issledovanii i paradigma sovremennoi arkheologii: Materialy Vserossiiskoi nauchnoi konferentsii, Moskva, 8-11 dekabrya 2015. M.: Yazyki slavyanskoi kul'tury, 2015. S. 8-18.

4. Vinogradov N. B. Stepi Yuzhnogo Urala i Kazakhstana v pervye veka II tys. do n. e. (pamyatniki sintashtinskogo i petrovskogo tipa). Chelyabinsk: Abris, 2011. $175 \mathrm{~s}$.

5. Epimakhov A. V. Yuzhnoe Zaural'e v epokhu srednei bronzy. Chelyabinsk: Izdatel'stvo YuUrGU, 2002. 170 s.

6. Tkachev V. V. Stepi Yuzhnogo Priural'ya i Zapadnogo Kazakhstana na rubezhe epokh srednei i pozdnei bronzy. Aktobe: Aktyubinskii oblastnoi tsentr istorii, etnografii i arkheologii, 2007.384 s.

7. Vinogradov N. B. Mogil'nik bronzovogo veka Krivoe Ozero v Yuzhnom Zaural'e. Chelyabinsk: Yuzhno-Ural'skoe knizhnoe izdatel'stvo, 2003. $362 \mathrm{~s}$.

8. Gening V. F., Zdanovich G. B., Gening V. V. Sintashta: arkheologicheskie pamyatniki ariiskikh plemen uralo-kazakhstanskikh stepei. Chelyabinsk: Yuzhno-Ural'skoe knizhnoe izdatel'stvo, 1992. $408 \mathrm{~s}$.

9. Drevnee Ust'e: ukreplennoe poselenie bronzovogo veka v Yuzhnom Zaural'e / Otv. red. N. B. Vinogradov. Chelyabinsk: Abris, 2013. $482 \mathrm{~s}$.

10. Epimakhov A. V. Rannie kompleksnye obshchestva severa Tsentral'noi Evrazii. Chelyabinsk: Chelyabinskii dom pechati, 2005. $192 \mathrm{~s}$. 


\section{Междисциплинарные исследования}

DOI: $10.7256 / 2222-1972.2016 .6 .20791$

11. Zdanovich G. B. Bronzovyi vek Uralo-Kazakhstanskikh stepei. Sverdlovsk: Ural'skii universitet, 1988. $184 \mathrm{~s}$.

12. Kupriyanova E. V., Zdanovich D. G. Drevnosti lesostepnogo Zaural'ya: mogil'nik Stepnoe VII. Chelyabinsk: Entsiklopediya, 2015. $196 \mathrm{~s}$.

13. Potemkina T. M. Bronzovyi vek lesostepnogo Pritobol'ya. M.: Nauka, 1985. 376 s.

14. Tkachev A. A. Tsentral'nyi Kazakhstan v epokhu bronzy. Tyumen': Tyumenskii neftegazovyi universitet, 2002. Ch. 1. $289 \mathrm{~s}$.

15. Degtyareva A.D. Drevnee metalloproizvodstvo Yuzhnogo Zaural'ya. Novosibirsk: Nauka, 2010. $162 \mathrm{~s}$.

16. Vinogradov N. B., Degtyareva A. D., Kuz'minykh S. V. Metallurgiya i metalloobrabotka v zhizni obitatelei ukreplennogo poseleniya Ust'e 1 // Vestnik arkheologii, antropologii i etnografii. 2013. № 3 (22). S. 4-30.

17. Chernykh E. N. Metall i drevnie kul'tury: Uzlovye problemy issledovaniya // Estestvennonauchnye metody v arkheologii. M.: Nauka, 1989. S. 14-30.

18. Chernykh E. N., Kuz'minykh S. V. Drevnyaya metallurgiya Severnoi Evrazii. M.: Nauka, 1989. 320 s.

19. Kalieva S. S., Logvin V. N. Mogil'nik u poseleniya Bestamak (predvaritel'noe soobshchenie) // Vestnik arkheologii, antropologii i etnografii. 2008. № 9. S. 32-58.

20. Logvin V. N. Mogil'nik Tokanai 1 i problema sootnosheniya «petrovskikh» i «sintashtinskikh» pamyatnikov // Zapadnaya i Yuzhnaya Sibir' v drevnosti. Barnaul: Izdatel'stvo Altaiskogo universiteta, 2005. S. 190-194.

21. Logvin A. V., Shevnina I. V. Kurgan Khalvai 3 (predvaritel'noe soobshchenie) // Margulanovskie chteniya 2011. Materialy mezhdunarodnoi arkheologicheskoi konferentsii. Astana: ENU imeni L. N. Gumileva, 2011. S. 291-296.

22. Morgunova N. L., Evgen'ev A. A., Kuptsova L. V. Pogrebal'nyi kompleks sintashtinskogo vremeni na poselenii Maloyuldashevo I v Zapadnom Orenburzh'e // Arkheologiya, etnografiya i antropologiya Evrazii. 2015. № 2 (43). S. 64-71.

23. Rovira S. Tekhnologiya vyplavki medi v epokhu pozdnei bronzy na Kargalakh // Rossiiskaya arkheologiya. 2005. № 4. S. 79-83.

24. Ryndina N. V. Drevneishee metalloobrabatyvayushchee proizvodstvo Yugo-Vostochnoi Evropy. M.: Editorial URSS, 1998. $288 \mathrm{s.}$

25. Degtyareva A. D., Grushin S. P., Shaikhutdinov V. M. Metalloobrabotka naseleniya eluninskoi kul'tury Verkhnei Obi (predvaritel'nye rezul'taty metallograficheskogo issledovaniya) // Vestnik arkheologii, antropologii i etnografii. 2010. № 2 (13). S. 27-35.

26. Degtyareva A. D., Kuz'minykh S. V. Rezul'taty analiticheskogo issledovaniya metallicheskikh izdelii mogil'nika Satyga XVI // Satyga XVI: seiminsko-turbinskii mogil'nik v taezhnoi zone Zapadnoi Sibiri. Ekaterinburg: Ural'skii rabochii, 2011. S. 37-44.

27. Gak E.I. Metalloobrabatyvayushchee proizvodstvo katakombnykh plemen stepnogo Predkavkaz'ya, Nizhnego Dona i Severskogo Dontsa: Avtoref. dis.... kand. ist. nauk. M.: MGU im. M.V. Lomonosova, 2005. 27 s.

28. Kitov E. P. Paleoantropologiya naseleniya Yuzhnogo Urala epokhi bronzy: Avtoref. dis. ... kand. ist. nauk. M.: Institut etnologii i antropologii RAN, 2011.26 s. 